\title{
Clinical Reasoning: A 10-year-old girl with muscle stiffness
}

Devin E. Prior, MD, and Partha S. Ghosh, MD

Neurology ${ }^{\circledR}$ 2020;95:e773-e778. doi:10.1212/WNL.0000000000010026

Correspondence

Dr. Ghosh

partha.ghosh@

childrens.harvard.edu

\section{Section 1}

A 10-year-old girl presented with episodic muscle stiffness for 4 years. Her muscles stiffened and became difficult to move with exertion, such as her legs after 30 minutes of playing soccer and her hands while carrying grocery bags. Symptoms were also provoked by cold temperature, such as swimming in a cold pool. After eating ice cream, she had difficulty speaking. She sometimes had persistent muscle stiffness for days after an episode. The patient had normal development and no significant medical history. Her father had a history of leg stiffness after playing soccer that started in his teens. On examination, she had normal muscle bulk and tone, with Medical Research Council 5/5 strength throughout bilateral proximal and distal extremity muscles. With tight grip of the hand and closure of the eyes, the patient had delayed relaxation of finger flexors and ocular muscles. Percussion of the thenar muscles, extensor digitorum communis, biceps, and gastrocnemius also provoked sustained muscle contraction. Reflexes were $2+$ and symmetric throughout and toes were downgoing. The remaining neurologic examination was unremarkable.

\section{Questions for consideration:}

1. What is the differential diagnosis?

2. What diagnostic testing should be considered? 


\section{Section 2}

The patient presented with episodic muscle stiffness triggered by exertion and cold temperature and had action and percussion myotonia. Myotonia is a key feature of myotonic dystrophies, nondystrophic myotonias (channelopathies), periodic paralysis disorders, and Schwartz-Jampel syndrome. ${ }^{1}$ However, myotonic dystrophy type 1 is a multisystem disease, presenting with characteristic facial features, often fixed weakness, and sometimes cognitive and behavioral symptoms in the childhood form as well as cardiac, pulmonary, and gastrointestinal manifestations. ${ }^{1}$ Myotonic dystrophy type 2 generally presents in adulthood with proximal muscle weakness and variable systemic symptoms. Schwartz-Jampel syndrome can present with myotonia but has prominent extramuscular features like short stature, bone dysplasia, joint contractures, and facial dysmorphism. ${ }^{1}$

Nondystrophic myotonic disorders caused by mutations of the muscle membrane voltage-gated ion channels present with myotonia and resultant muscle stiffness similar to this patient. As shown in the figure, these disorders lack extramuscular features and fixed weakness and may be classified by the distribution and triggering factors for myotonia. ${ }^{2}$ Myotonia congenita is a chloride channelopathy (CLCN1) with diffuse myotonia, worsened by rest and improved with exertion, described as a warm up phenomenon. The autosomal dominant myotonia congenita shows more upper limb involvement, while the recessive form is more prominent in the lower limbs. ${ }^{2}$ In paramyotonia congenita (PMC), an autosomal dominant sodium channel disorder (SCN4A), myotonia is diffuse, most prominent in the eyes, face, hands, and sometimes legs, and is exacerbated by exercise and cold temperature. Involved muscles can be stiff for hours or days during an attack. ${ }^{2}$ Other sodium channel myotonic disorders (SNC4A), all autosomal dominant, include potassium-aggravated myotonia triggered by potassium-rich food, acetazolamide-responsive myotonia showing improvement with acetazolamide, myotonia fluctuans in which symptoms can vary greatly in severity and muscle stiffness can be delayed after exercise, and myotonia permanens with severe, persistent myotonia. ${ }^{3}$ Hyperkalemic periodic paralysis, another

Figure Clinical and electrodiagnostic features differentiating childhood myotonic disorders

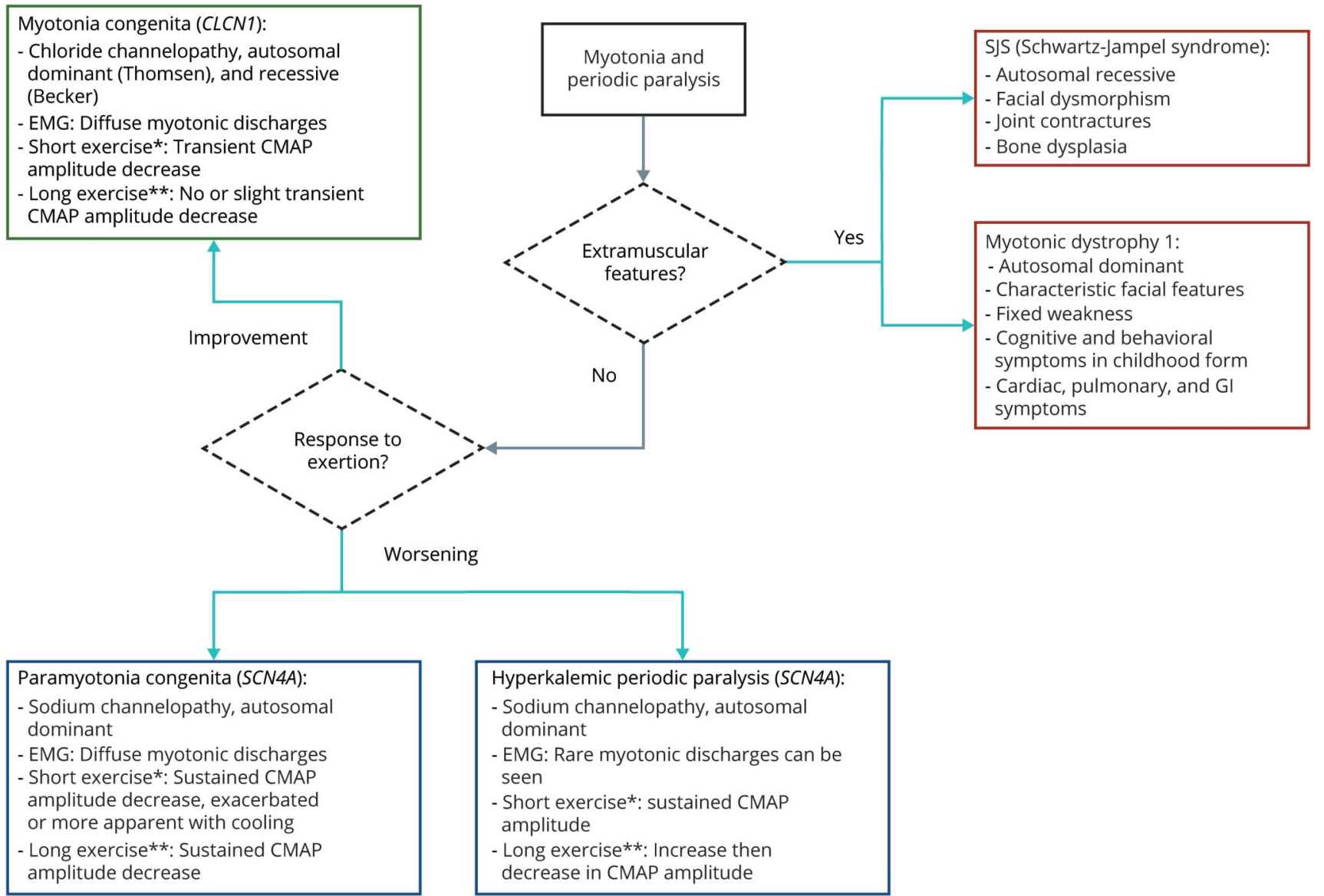

*Short exercise: (1) baseline compound muscle action potential (CMAP) amplitude recorded, (2) 10 seconds of isometric muscle contraction, (3) CMAP recorded 2 seconds after exercise, then every 10 seconds for 1 minute, (4) repeat 3 trials. **Long exercise: (1) baseline CMAP amplitude recorded, (2) 5 minutes of exercise, (3) CMAP recorded after exercise, every minute for 5 minutes, then every 5 minutes for $40-45$ minutes. Gl $=$ gastrointestinal. 
autosomal dominant sodium channelopathy (SCN4A), is defined primarily by attacks of flaccid paralysis often affecting the lower extremities, which can be related to exertion, though are often triggered by fasting, potassiumcontaining foods, and rest after exercise. Some patients with hyperkalemic periodic paralysis may also show clinical or electrical myotonia. ${ }^{2}$
In the described patient, myotonic dystrophy type 1 and Schwartz-Jampel syndrome are unlikely given the lack of extramuscular features. The triggering factors of cold and exercise favor a diagnosis of PMC. Electrodiagnostic testing would help to clarify the pattern of myotonia and confirm absence of myopathy. Furthermore, specialized testing including exercise tests and cooling can show characteristic findings of each disorder. ${ }^{4}$

GO TO SECTION 3 


\section{Section 3}

The patient had laboratory testing 2 days following an episode of leg muscle stiffness and weakness induced by playing in a cold waterslide. Creatine kinase was elevated at 1,668 U/L $(0-200 \mathrm{U} / \mathrm{L})$, and aldolase at $18.5 \mathrm{U} / \mathrm{L}(0-12)$, which normalized after 2 weeks. Electrodiagnostic studies showed normal baseline motor and sensory responses of the right upper extremity. In short exercise testing, after a baseline compound muscle action potential (CMAP) amplitude was recorded, the patient contracted the muscle isometrically for 10 seconds, and repeat CMAPs were recorded immediately after exercise, then every 10 seconds for 1 minute. ${ }^{3}$ Ulnar CMAP amplitude decreased from $7.1 \mathrm{mV}$ at baseline to $2.4 \mathrm{mV}$ immediately after short exercise, remaining low at 1.6-1.7 with subsequent trials for 1 minute. After cold exposure, ulnar CMAP amplitude decreased to $1.5 \mathrm{mV}$. Patient cooperation limited the ability to perform repeat short exercise trials or long exercise testing in which 5 minutes of exercise is performed and repeat CMAPs are recorded immediately after exercise, then every minute for 5 minutes, followed by every 5 minutes for $40-45$ minutes. ${ }^{4}$ Needle EMG showed diffuse electrical myotonia in the tibialis anterior, vastus medialis, biceps, and first dorsal interosseous. Motor unit potentials appeared normal.

\section{Questions for consideration:}

1. What diagnosis is suggested by the electrodiagnostic testing?

2. What is the next step for diagnostic confirmation? 


\section{Section 4}

Myotonia congenita, paramyotonia, and hyperkalemic periodic paralysis differ in the patterns of abnormalities on electrodiagnostic testing due to underlying ion channel dysfunction and resultant changes in depolarization and excitability. ${ }^{4}$

Myotonia congenita results from chloride channel mutations that decrease its conductance, altering membrane potential due to potassium induced after depolarization that blocks further membrane excitability, resulting in myotonia and weakness. ${ }^{2}$ Repeated or prolonged exercise can restore blocked muscle membrane excitability and short exercise testing shows a CMAP amplitude decrease immediately after exercise that returns to normal values 20-40 seconds following exercise and is not observed with repeat trials or with long exercise testing, as summarized in the figure. ${ }^{4}$

PMC results from mutations that cause a gain of function of the sodium channel disrupting its inactivation, increasing sodium current, causing prolonged depolarization and ultimately inexcitability. ${ }^{2}$ Repeated short or prolonged exercise testing is predicted to induce this prolonged depolarization and inexcitability. Therefore PMC shows a persistent decrease in CMAP amplitude following short and long exercise. ${ }^{4}$

Hyperkalemic periodic paralysis similarly results from mutations that increase sodium current; however, larger persistent currents are required to cause depolarization and inexcitability. ${ }^{2}$ With short and initially long exercise, the membrane may be properly repolarized by increased activity of other ion channels and pumps, but later, reduced membrane excitability results in weakness. Hyperkalemic periodic paralysis shows a persistent increase in CMAP amplitude following short duration exercise and a slight, transient increase immediately after long exercise, then a decrease in CMAP amplitude after $10-20$ minutes. $^{4}$

Cooling can result in an over 75\% CMAP amplitude decrease in PMC but has no effect on the other disorders. ${ }^{5}$ With needle EMG, myotonia congenita and paramyotonia show diffuse myotonic discharges whereas hyperkalemic periodic paralysis shows only a few short-duration myotonic discharges, if any. ${ }^{4}$

Electrodiagnostic testing can be time-intensive and uncomfortable, making it difficult for many children to tolerate. Based on the clinical information, highest yield testing included short exercise testing and cooling to differentiate nondystrophic myotonias. This patient's sustained ulnar CMAP amplitude decrement with short exercise testing and CMAP amplitude drop with cooling are most consistent with PMC. The diffuse myotonia on EMG would make hyperkalemic periodic paralysis less likely but would not discriminate between myotonia congenita and paramyotonia. For diagnostic confirmation, the patient underwent genetic testing that showed a known pathogenic mutation in the SCN4A gene (c3938C > T, pThr1313Met). Parental testing was declined by the family. Treatment with mexiletine was offered but the family decided against it. On follow-up, she was doing better with precautions about cold exposure.

\section{Discussion}

As shown in the figure, PMC can be differentiated based on history, particularly identifying triggers and relieving factors and characteristic electrodiagnostic findings. ${ }^{6}$ DNA-based testing is important to confirm an exact genetic diagnosis and guide genetic counseling. Muscle biopsy is of little utility as histologic findings such as myopathic changes and tubular aggregates are nonspecific. ${ }^{2}$

With mild symptoms, patients may be advised to avoid triggers such as cold and strenuous exercise. However, patients with paramyotonia often have symptoms that impact quality of life and result in disability and unemployment. ${ }^{7}$ Although there are no Food and Drug Administration-approved treatments, sodium channel blockers including antiepileptics, anesthetics, and antiarrhythmics are often used, which reduce membrane excitability and resultant myotonia. Mexiletine, the most common agent, has been shown to reduce electrical myotonia, improve muscle stiffness, and improve the quality of life. Given its potential to cause arrhythmias, patients should undergo monitoring with electrocardiogram. ${ }^{8}$

Patients with PMC have normal lifespan and do not have systemic extramuscular involvement in contrast to myotonic dystrophy. ${ }^{7}$ In the surgical setting, myotonia may be triggered by specific induction agents causing intubation difficulties and volatile agents can lead to postoperative shivering and then myotonia. ${ }^{9}$ Depolarizing anesthetic agents such as suxamethonium chloride should be avoided in channelopathies. ${ }^{3}$ Although uncommon, patients are at risk for malignant hyperthermia. ${ }^{9}$ As in this case, creatine kinase can be elevated during attacks of muscle stiffness, indicating risk for rhabdomyolysis. ${ }^{10}$

\section{Study funding}

No targeted funding reported.

\section{Disclosure}

D.E. Prior reports no disclosures. P.S. Ghosh has received consulting fees from CVS Caremark, Sarepta, PTC, and Catalyst Pharmaceuticals. Go to Neurology.org/ $\mathrm{N}$ for full disclosures.

Appendix Authors

\begin{tabular}{lll}
\hline Name & Location & Contribution \\
\hline $\begin{array}{l}\text { Devin E. } \\
\text { Prior, MD }\end{array}$ & $\begin{array}{l}\text { Lahey Clinic, } \\
\text { Burlington, MA }\end{array}$ & $\begin{array}{l}\text { Acquisition of data, analysis and } \\
\text { interpretation }\end{array}$ \\
\hline $\begin{array}{l}\text { Partha S. } \\
\text { Ghosh, MD }\end{array}$ & $\begin{array}{l}\text { Boston } \\
\text { Children's } \\
\text { Hospital, MA }\end{array}$ & $\begin{array}{l}\text { Study concept and design, analysis and } \\
\text { interpretation, critical revision of the } \\
\text { manuscript for important intellectual } \\
\text { content, study supervision }\end{array}$ \\
\hline
\end{tabular}




\section{References}

1. Sansone VA. The dystrophic and nondystrophic myotonias. Continuum 2016;22: 1889-1915.

2. Raja Rayan DL, Hanna MG. Skeletal muscle channelopathies: nondystrophic myotonias and periodic paralysis. Curr Opin Neurol 2010;23:466-476.

3. Statland JM, Barohn RJ. Muscle channelopathies: the nondystrophic myotonias and periodic paralyses. Continuum 2013;19:1598-1614.

4. Fournier E, Arzel M, Sternberg D, et al. Electromyography guides toward subgroups of mutations in muscle channelopathies. Ann Neurol 2004;56:650-661.

5. Miller TM. Differential diagnosis of myotonic disorders. Muscle Nerve 2008;37: 293-299.
6. Cannon SC. Sodium channelopathies of skeletal muscle. Handb Exp Pharmacol 2018; 246:309-330.

7. Trivedi JR, Bundy B, Statland J, et al. Non-dystrophic myotonia: prospective study of objective and patient reported outcomes. Brain 2013;136:2189-2200.

8. Phillips L, Trivedi JR. Skeletal muscle channelopathies. Neurotherapeutics 2018; 15: 954-965.

9. Najid NM, Razak TA, Günaydın DB. Analgesia and anaesthesia management of labour and caesarean delivery for a parturient with paramyotonia congenita. Turk J Anaesthesiol Reanim 2019;47:345-347.

10. Hahn C, Salajegheh MK. Myotonic disorders: a review article. Iran J Neurol 2016;15: $46-53$. 


\title{
Neurology
}

\author{
Clinical Reasoning: A 10-year-old girl with muscle stiffness \\ Devin E. Prior and Partha S. Ghosh \\ Neurology 2020;95;e773-e778 Published Online before print June 17, 2020 \\ DOI 10.1212/WNL.0000000000010026
}

This information is current as of June 17, 2020

Updated Information \& Services

References

Subspecialty Collections

Permissions \& Licensing

Reprints including high resolution figures, can be found at: http://n.neurology.org/content/95/6/e773.full

This article cites 10 articles, 0 of which you can access for free at: http://n.neurology.org/content/95/6/e773.full\#ref-list-1

This article, along with others on similar topics, appears in the following collection(s):

All Clinical Neurology

http://n.neurology.org/cgi/collection/all_clinical_neurology Muscle disease

http://n.neurology.org/cgi/collection/muscle_disease

Information about reproducing this article in parts (figures,tables) or in its entirety can be found online at:

http://www.neurology.org/about/about_the_journal\#permissions

Information about ordering reprints can be found online:

http://n.neurology.org/subscribers/advertise

Neurology ${ }^{\circledR}$ is the official journal of the American Academy of Neurology. Published continuously since 1951, it is now a weekly with 48 issues per year. Copyright @ 2020 American Academy of Neurology. All rights reserved. Print ISSN: 0028-3878. Online ISSN: 1526-632X.

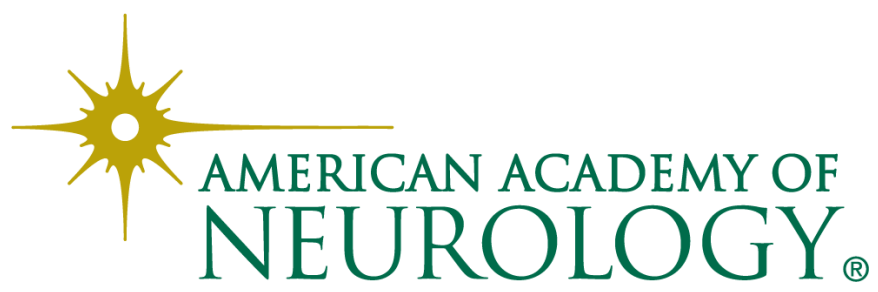

